\title{
A Comparative Study on Estimation of the Earth's Albedo and Its Variation with other Meteorological Parameters between two Tropical Stations in Nigeria
}

\author{
Davidson Odafe Akpootu $^{1^{*}}$, Okpala Chidozie Nnaemeka ${ }^{2}$, Samuel Adesina Fagbemi ${ }^{3}$, Mukhtar Isah \\ Iliyasu $^{4}$, Isaac Obiajulu Onwubuya ${ }^{5}$, Simeon Imaben Salifu ${ }^{6}$ and Musa Garba ${ }^{7}$ \\ ${ }^{1}$ Department of Physics, Usmanu Danfodiyo University, Sokoto, Nigeria \\ ${ }^{2}$ Department of Physics, Federal University Dutsin-ma, Katsina, Nigeria \\ ${ }^{3}$ Department of Physics, Ahmadu Bello University, Zaria, Nigeria \\ ${ }^{4}$ Physics Unit, Umaru Ali Shinkafi Polytechnic, Sokoto, Nigeria \\ ${ }^{5}$ Airforce Institute of Technology, Kaduna, Nigeria \\ ${ }^{6}$ Department of Physics, Kogi State College of Education Technical Kabba, Nigeria \\ ${ }^{7}$ Department of Physics, National Open University, Bauchi Study Centre, Nigeria
}

\begin{abstract}
Estimation of albedo is paramount in the evaluation of solar energy collectors, atmospheric radiative transfer and studies that relates to atmospheric thermal balance. This study, employed the shortwave solar energy balancing at the edge of the Earth's atmosphere to estimate and compare the variation of albedo for two locations, Gusau (Latitude 12.170N, Longitude 6.700E and altitude $463.9 \mathrm{~m}$ above sea level) and Calabar (Latitude 4.970N, Longitude 8.350E and altitude $61.9 \mathrm{~m}$ above sea level) situated across the Sahelian and Coastal climatic zones of Nigeria respectively using measured monthly mean daily meteorological parameter of global solar radiation obtained from the National Aeronautics and Space Administration (NASA) during the period of twenty two years (July 1983 - June 2005). The variation of albedo with clearness index, relative humidity and mean temperature were investigated. The variation of emitting Earth's surface temperature and maximum wavelength for each location were also investigated. The results in this study revealed that the estimated surface albedo depicts a direct opposite relationship with the clearness index, an inverse relationship with the emitting Earth's surface temperature and a direct relationship with the wavelength for the studied locations. The highest and lowest values of albedo simulated for Gusau was in the months of August and February with 0.4933 and 0.3270 respectively, while for Calabar are in the months of August and January with 0.6949 and 0.4218 respectively; the estimated albedo obtained for Calabar in this study are more than that of Gusau throughout the months for the period under investigation suggesting that as the location's latitude and global solar radiation increases the albedo or reflectance decreases. The variation of clearness index with albedo for Gusau suggests the availability of abundant global solar radiation throughout the months in the region while for Calabar revealed the availability of abundant global solar radiation only in the months of January, February and December. The emitting Earth surface temperature for Gusau ranged between $235.1297 \mathrm{~K}$ in August and 252.4133 K in February while for Calabar ranged between 207.1236 K in August and 243.0097 K in January, these values agrees closely to the standard emitting Earth surface temperature value $(255.0000 \mathrm{~K})$. The maximum emitting wavelength values for both locations revealed that the radiation is longwave and are found within the infrared region of the electromagnetic spectrum. The variation of relative humidity with albedo depicts almost a similar trend for both locations. The results showed that as albedo increases during the rainy season the mean temperature decreases.
\end{abstract}

Keywords: Albedo, Global Solar Radiation, Earth Surface Temperature, Maximum Wavelength, NASA

\section{INTRODUCTION}

Solar radiation data has been considered as an essential requirement to conduct feasibility studies for solar energy systems [1]. Among the renewable energy resources, only solar energy has the greatest potentiality, availability and is free from environmental 
hazard [2]. Over the years, the amount of solar radiation reaching the Earth's surface is being modified through reflection, scattering and absorption in the atmosphere. The fraction of the incident solar radiation that is reflected and scattered back into space is called albedo [1].

Albedo is related to reflection of solar radiation at a surface and therefore defined in terms of it, as the ratio of the reflected solar radiation to the incident solar radiation at the surface, i.e., $\mathrm{H}_{\mathrm{r}} / \mathrm{H}_{0}$ [1]. The extraterrestrial radiation, $\mathrm{H}_{0}$ at the edge of the atmosphere, from the sun, is considered the incident solar radiation. Albedo or reflection coefficient is also known as reflectance or reflectivity of a surface; by this, the surface albedo of the Earth is regarded the same as planetary albedo by many scientists [3]. The average overall albedo of the Earth, its planetary albedo, is about 0.3 . This fraction of incoming radiation is reflected back into space. The other 0.7 part of the incoming solar radiation is absorbed by our planet [4]. It is assumed however that the reflected radiation, $\mathrm{H}_{\mathrm{r}}$, is both diffuse and specular in nature, that is, it is diffuse if the reflected radiation is uniform or isotropic in all angular directions, and specular if the surface of reflection is smooth with respect to the wavelength of the incident radiation such that the laws of reflection are satisfied [3]. It was reported by Gutman [5] that the observed albedo assumed that the radiation field is isotropic. Albedo, as a property of a surface, therefore, can be used to determine the brightness of a surface. According to Prado and Ferreira [6], materials with high albedo and emittance attain low temperature when exposed to solar radiation, and therefore reduce transference of heat to their surroundings. Thus albedo is an important input parameter or quantity in evaluating the total insolation on a building or a solar energy collector. It is also important in the studies dealing with thermal balance in the atmosphere. The Earth's albedo affects the amount of Sun-light the planet absorbs. It plays a major role in the energy balance of the Earth's surface, as it defines the rate of the absorbed portion of the incident solar radiation. Hence, it has a direct effect on Earth's energy budget and, therefore, global temperatures. If the Earth receives more energy from the Sun than it sends back to space, the Earth gets warmer. On the other hand, if the Earth reflects more of the Sun's energy than it absorbs, the Earth gets colder. Some studies on the albedo of the Earth's atmosphere for different locations have been investigated.

Audu et al. [7] estimated the albedo for Kano, Nigeria. In their studies they obtained maximum albedo of 0.58 in August (the peak of cloud activity) while the minimum albedo of 0.41 in November (the onset of dry season) using global solar radiation data for Kano, Nigeria during the period of 34 years (1977-2010) obtained from the International Institute for Tropical Agriculture, Ibadan, Nigeria. In the study carried out by Babatunde et al. [4] they obtained the albedo for Ilorin, Nigeria ranging between 0.361 and 0.644 using global solar radiation data measured at the Department of Physics in the year 2000. The highest albedo recorded was 0.644 at the peak period of cloud activity in August and the lowest was 0.361 in November when it was relatively cloudless and dustless. Seven years later the study carried out by Babatunde et al [4] was expanded by the leading author, Babatunde [8] and he confirmed the values of albedo obtained, however, was approximated. In another development, Audu and Isikwue [9] adopt the model for shortwave solar energy balancing at the edge of Earth atmosphere to estimate the albedo for Makurdi, Nigeria. The results indicated that the highest albedo of 0.7 in August and the lowest of 0.5 in November were estimated using global solar radiation data covering the period (2000-2010) obtained from the Air Force Base, Makurdi, Nigeria. In a related study De Sonsa et al. [10] obtained albedo at Maceio, Brazil as 0.47 and 0.41 during the rainy and dry seasons respectively. More recently, Akpootu and Iliyasu [1] adopt the shortwave solar energy balancing at the edge of Earth atmosphere to estimate the variation of albedo for Sokoto using measured monthly parameter of global solar radiation during the period of thirty one years (1980 - 2010). The results in their study showed that the highest and lowest values of albedo simulated for Sokoto were found to be in the months of August and November with 0.4925 and 0.3185 respectively. In another study, Barka et al. [11] proposed a multivariate model that uses temperature and relative humidity linear relationship to determine the albedo of some selected sites in the Republic of Chad. They obtained RMSE, MAE and MAPE values of 0.035, 0.027 and 7.58 respectively.

The purpose of this study is (i) to estimate and compare the surface albedo for two tropical locations namely, Gusau and Calabar situated across the Sahelian and Coastal climatic zones of Nigeria respectively. (ii) to investigate the variation of albedo with clearness index, relative humidity and temperature for the locations (iii) compare the monthly mean emitting Earth surface temperature for the locations to the standard value (iv) to investigate the type of radiation found in the electromagnetic spectrum considering the values of the maximum wavelength obtained for the locations.

\section{METHODOLOGY}

The measured monthly averaged daily climatic data of global solar radiation, relative humidity, minimum and maximum temperature meteorological data used in this study were obtained from the National Aeronautics and Space Administration (NASA) atmospheric science data centre under Surface meteorology and Solar Energy. The daily averaged data were aggregated to monthly data. The mean temperature was obtained by taken the average of the minimum and maximum temperature. The study area under investigation is Gusau (Latitude $12.17^{\circ} \mathrm{N}$, Longitude $6.70^{\circ} \mathrm{E}$ and altitude $463.9 \mathrm{~m}$ above sea level) located in Sahelian zone of Nigeria and Calabar (Latitude $4.97^{\circ} \mathrm{N}$, Longitude $8.35^{\circ} \mathrm{E}$ and altitude $61.9 \mathrm{~m}$ above sea level) located in the Coastal zone 
of Nigeria. To avoid possible misleading indications related to year to year variation in weather condition, the period under investigation is twenty two years (July 1983 - June 2005) so that a good climatological average is assured. The quality assurance of the meteorological measurements was determined by checking the overall consistency of the daily and monthly average of the meteorological parameter used in the study locations. Nigeria being a tropical region has two seasons - the wet and the dry. The wet season is characterized by heavy rainfall. The season falls between the months of April and October. The dry season, on the other hand, is characterized by scanty or no rainfall and dry dust laden atmosphere. The season falls between the month of November and March [12]. According to Olaniran [13] Nigeria is classified into four climatic zones; these are the Sahelian zone, Midland zone, Guinea savannah zone and the Coastal zone. The locations within the climatic zones are shown in Figure 1.

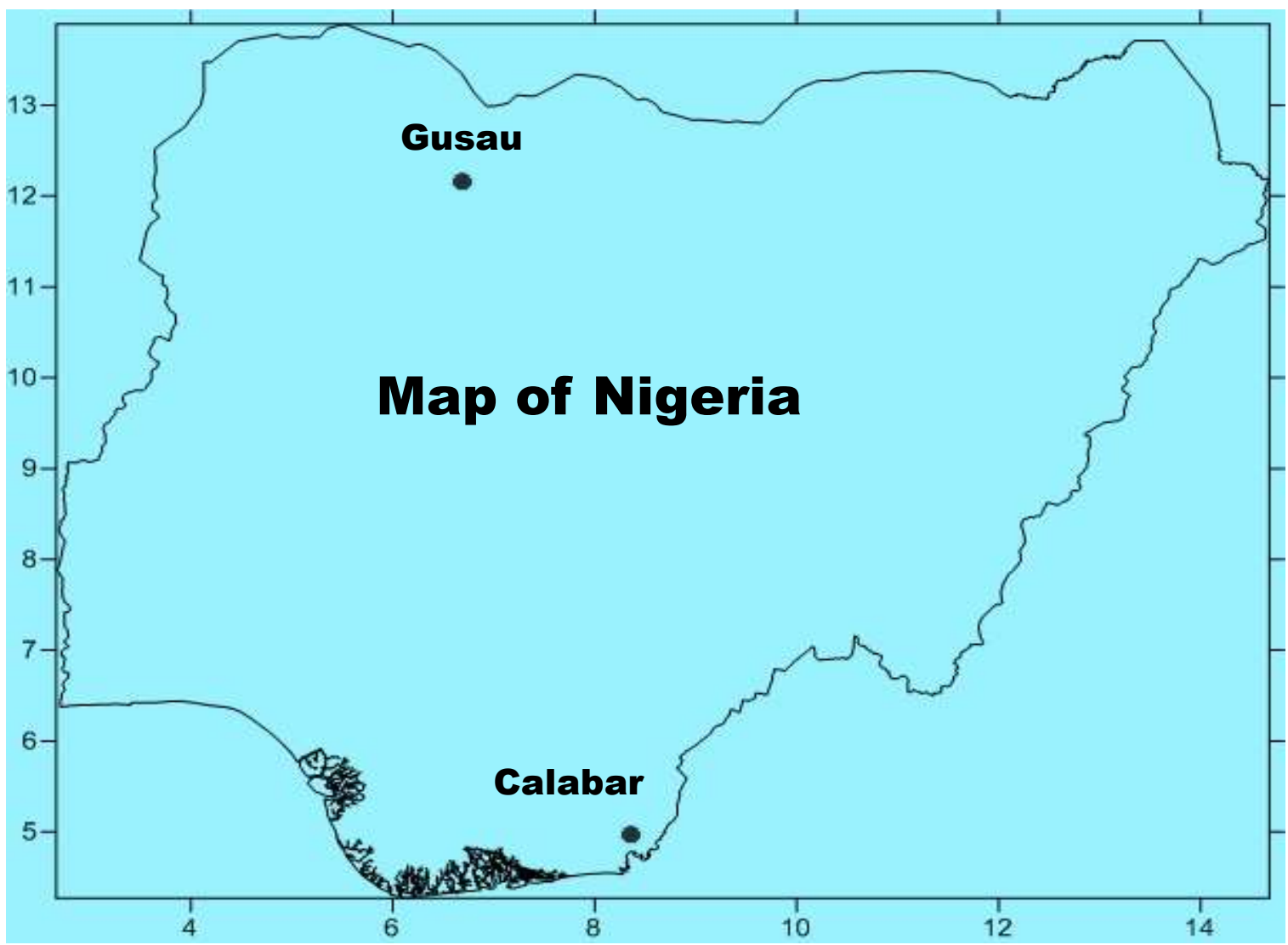

Figure 1. Map of Nigeria showing the locations under investigation

The extraterrestrial radiation, $H_{0}$ is the solar radiation received at the top of the Earth's atmosphere from the sun on a horizontal surface and is considered as the incident solar radiation [14].

The monthly average daily extraterrestrial radiation on a horizontal surface $\left(H_{o}\right)$ in $\mathrm{MJ} / \mathrm{m}^{2} /$ day can be calculated for days giving average of each month from the following equation [3,15]:

$$
H_{o}=\left(\frac{24}{\pi}\right) I_{s c}\left[1+0.033 \cos \left(\frac{360 n}{365}\right)\right]\left[\cos \varphi \cos \delta \sin \omega_{s}+\left(\frac{2 \pi \omega_{s}}{360}\right) \sin \varphi \sin \delta\right]
$$

where $I_{s c}$ is the solar constant $\left(=1367 \mathrm{Wm}^{-2}\right), \varphi$ is the latitude of the site, $\delta$ is the solar declination and $\omega_{s}$ is the mean sunrise hour angle for the given month and $n$ is the number of days of the year starting from $1^{\text {st }}$ of January to $31^{\text {st }}$ of December. The solar declination, $\delta$ and the mean sunrise hour angle, $\omega_{s}$ can be calculated using the following equation [3, 15]:

$$
\begin{aligned}
& \delta=23.45 \sin \left\{360\left(\frac{284+n}{365}\right)\right\} \\
& \omega_{s}=\cos ^{-1}(- \text { tan } \varphi \tan \delta)
\end{aligned}
$$

According to Babatunde [16], the shortwave solar energy balancing at the edge of the Earth's atmosphere can be computed using the expression: 
International Journal of Advances in Scientific Research and Engineering (ijasre), Vol 6 (2), February-2020

$$
\frac{H_{m}}{H_{0}}+\frac{H_{a}}{H_{0}}+\frac{H_{r}}{H_{0}}=1
$$

where $H_{m}$ is the measured global solar radiation in $\mathrm{MJ} / \mathrm{m}^{2} /$ day, the ratio $\frac{H_{m}}{H_{0}}$ is the fraction of the extraterrestrial radiation transmitted through the atmosphere to the ground surface, and is known as the clearness index [17, 18], $H_{a}$ is the absorbed solar radiation, the ratio $\frac{H_{a}}{H_{0}}$ is the solar energy fraction absorbed, and is known as the absorption co-efficient or absorbance, and $\frac{H_{r}}{H_{0}}$ is the solar energy fraction reflected back to space, and is known as the reflection co-efficient or reflectance [16] and $H_{r}$ is the shortwave reflected radiation. According to the study carried out by Babatunde [16]. The ratio $\frac{H_{a}}{H_{0}}$ was found to be very small in value compared with the other ratios given in equation (4) and therefore negligible, i.e., $\frac{H_{a}}{H_{0}} \ll 1$

Therefore equation (4) becomes

$$
\frac{H_{m}}{H_{0}}+\frac{H_{r}}{H_{0}} \approx 1
$$

From equation (5), the reflectivity or albedo can be estimated using the expression as

$$
\frac{H_{r}}{H_{0}}=1-\frac{H_{m}}{H_{0}}
$$

The flux density of longwave radiation emitted by the Earth, $F_{E}$, given by the Stefan-Boltzmann law [19] is expressed as

$$
F_{E}=\sigma T_{E}^{4}
$$

where $\sigma$ is the universal Stefan-Boltzman constant, $\sigma=5.67 \times 10^{-8} \mathrm{Wm}^{-2} \mathrm{~K}^{-4}$ and $T_{E}$ is the Earth's temperature, in Kelvin (K). $F_{E}$ is also given [19] as

$$
F_{E}=\frac{\left(1-\frac{H_{r}}{H_{0}}\right) F_{S}}{4}
$$

where $\frac{H_{r}}{H_{0}}$ is the planetary albedo of the Earth for the study area and $F_{S}$ is the flux density of solar radiation incident upon the Earth $\left(1368 \mathrm{Wm}^{-2}\right)$.

Combining equations (7) and (8), the following equation was obtained that relates the surface temperature of the Earth, $T_{E}$ to its albedo for the study locations $[19,20]$ as

$$
T_{E}=\left[\left(\frac{\left(1-\frac{H_{r}}{H_{0}}\right) F_{s}}{4 \sigma}\right)\right]^{1 / 4}
$$

The equation given in (9) indicates that the temperature $T_{E}$ would decrease as albedo increases.

In atmospheric science the term "shortwave" $(\lambda<4 \mu \mathrm{m})$ refers to the wavelength band that carries most of the energy associated with solar radiation and "longwave" $(\lambda>4 \mu \mathrm{m})$ refers to the band that encompasses most of the terrestrial (Earth-emitted) radiation [19]. In the radiative transfer literature, the spectrum is typically divided into the regions shown in Figure 2. The relatively narrow visible region, which extends from wavelengths of 0.39 to $0.76 \mu \mathrm{m}$, is defined by the range of wavelengths that the human eye is capable of sensing [19]. The near infrared region, which extends from the boundary of the visible up to $\sim 4 \mu m$, is dominated by solar radiation,whereas the remainder of the infrared region is dominated by terrestrial (i.e., Earth emitted) radiation [19]. Microwave radiation is not important in the Earth's energy balance but it is widely used in remote sensing because it is capable of penetrating through clouds [19].

The maximum wavelength of emission at temperature, $T_{E}$ is given by the Wien's displacement law [19] as

$$
\lambda_{m}=\frac{2897}{T_{E}}
$$

$\lambda_{m}$ is expressed in micrometers and $T_{E}$ in Kelvin. 


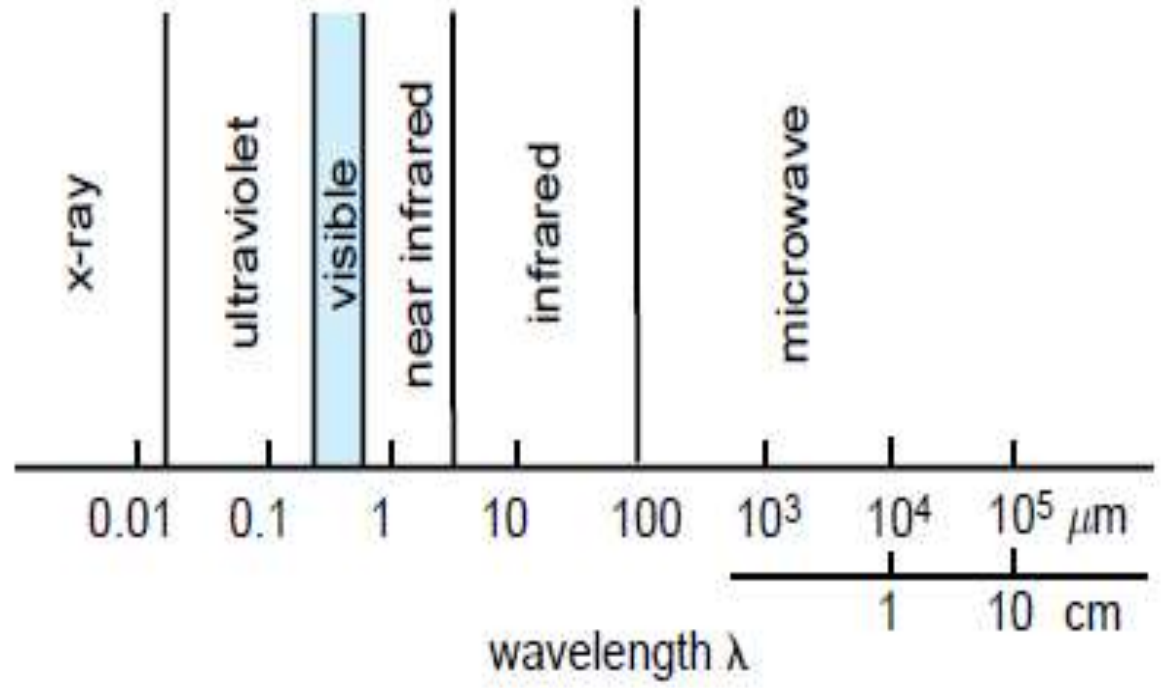

Figure 2. The electromagnetic spectrum [19]

\section{RESULTS AND DISCUSSION}

Table 1. Monthly mean meteorological parameters for Gusau

\begin{tabular}{cccc}
\hline Month & $\mathrm{H}_{\text {mea }}\left(\mathrm{MJm}^{-2} \mathrm{day}^{-1}\right)$ & $\mathrm{RH}(\%)$ & $\mathrm{T}_{\text {mean }}\left({ }^{0} \mathrm{C}\right)$ \\
\hline January & 19.7971 & 15.8990 & 23.8667 \\
February & 22.6567 & 14.4270 & 25.6269 \\
March & 24.1145 & 23.1835 & 28.6017 \\
April & 24.6174 & 43.1662 & 29.5042 \\
May & 24.1246 & 61.2077 & 28.3980 \\
June & 23.3990 & 76.2176 & 26.1061 \\
July & 20.4644 & 81.7522 & 24.8295 \\
August & 19.1225 & 81.2932 & 24.8150 \\
September & 20.6228 & 76.9805 & 25.5309 \\
October & 21.3928 & 53.2214 & 26.9423 \\
November & 20.4428 & 21.6322 & 26.8410 \\
December & 18.8926 & 17.2176 & 24.4835 \\
\hline Mean & $\mathbf{2 1 . 6 3 7 3}$ & $\mathbf{4 7 . 1 8 3 2}$ & $\mathbf{2 6 . 2 9 5 5}$ \\
\hline
\end{tabular}

Table 2. Monthly mean meteorological parameters for Calabar

\begin{tabular}{cccc}
\hline Month & $\mathrm{H}_{\text {mea }}\left(\mathrm{MJm}^{-2} \mathrm{day}^{-1}\right)$ & $\mathrm{RH}(\%)$ & $\mathrm{T}_{\text {mean }}\left({ }^{0} \mathrm{C}\right)$ \\
\hline January & 19.7911 & 76.5317 & 25.1333 \\
February & 20.5331 & 78.2678 & 25.4831 \\
March & 17.8988 & 82.5394 & 25.5098 \\
April & 16.6275 & 83.7085 & 25.6170 \\
May & 15.5371 & 84.6878 & 25.4788 \\
June & 12.9632 & 84.8498 & 24.6783 \\
July & 11.4898 & 84.2080 & 23.8383 \\
August & 11.2041 & 84.9356 & 23.6143 \\
September & 11.7428 & 86.3630 & 23.8736 \\
October & 13.0639 & 86.5349 & 24.2012 \\
November & 15.4424 & 84.6653 & 24.5426
\end{tabular}


International Journal of Advances in Scientific Research and Engineering (ijasre), Vol 6 (2), February-2020

\begin{tabular}{llll} 
December & 18.4972 & 80.2082 & 24.9147 \\
\hline Mean & $\mathbf{1 5 . 3 9 9 3}$ & $\mathbf{8 3 . 1 2 5 0}$ & $\mathbf{2 4 . 7 4 0 4}$ \\
\hline
\end{tabular}

Table 1 and 2 shows the meteorological parameters and the mean values for Gusau and Calabar during the period under study. It can be seen that the yearly mean monthly global solar radiation and mean temperature for Gusau are higher than Calabar except for the relative humidity as this variation is expected for Sahelian and Coastal regions.

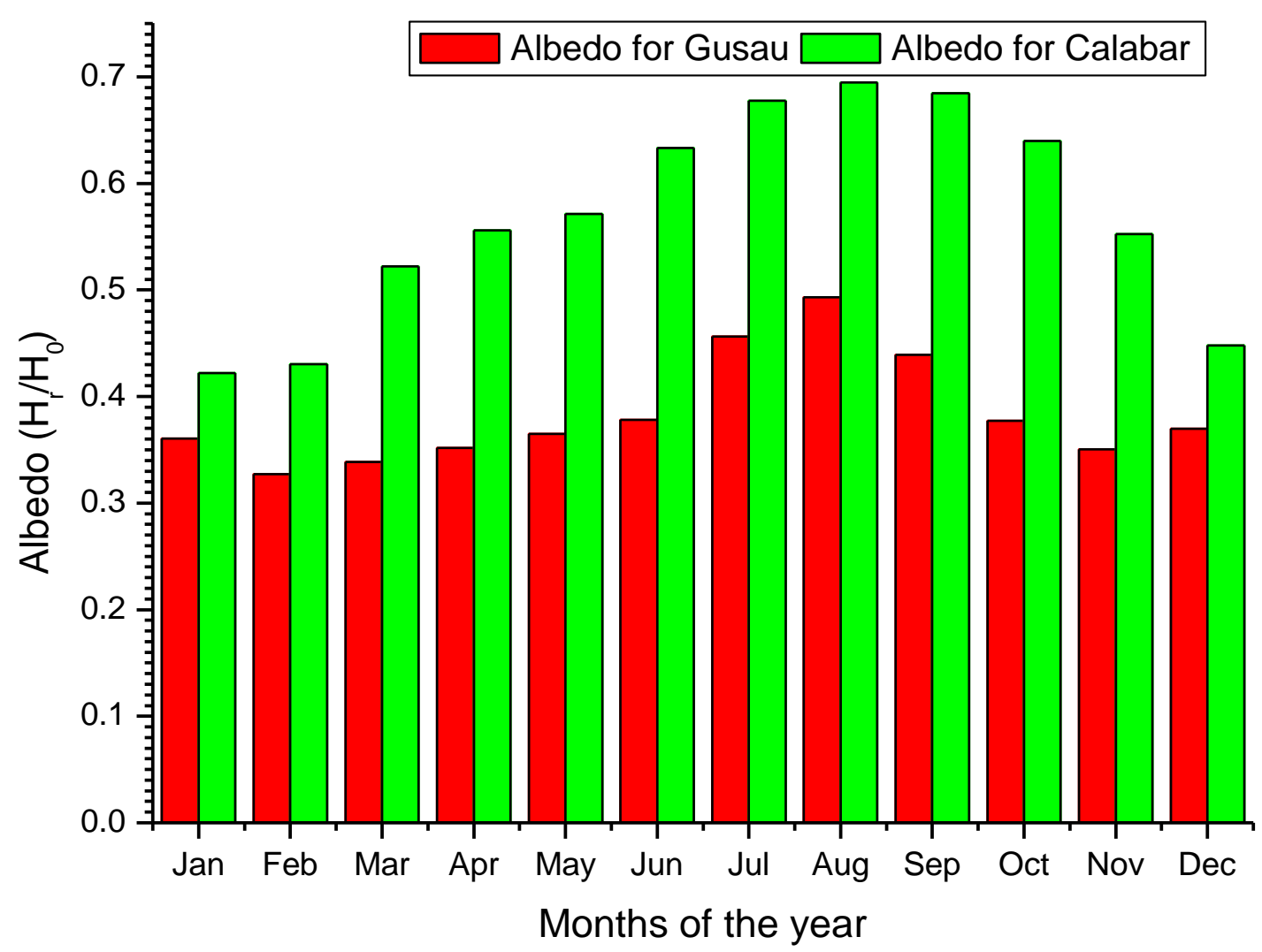

Figure 3. Comparison between Albedo for Gusau and Calabar

Figure 3 shows the comparison of the monthly average daily planetary albedo between Gusau and Calabar. The figure indicates that high values of albedo were observed in the months of July, August and September for both locations. The highest and lowest values of albedo was observed in the months of August and February for Gusau with 0.4933 and 0.3270 relatively while for Calabar the highest and lowest values of albedo were found in the months of August and January with 0.6949 and 0.4218 respectively. The highest values of albedo recorded in the month of August shows that this is the month where we have the peak of rainy season in the study locations and a predominantly cloudy month, attest to the fact that reflection of solar radiation by the planet Earth in this region, are mostly due to clouds, aerosols and air molecules of which cloud is the major contributor. The surface albedo obtained for Gusau ranged between 0.3270 and 0.4933 while for Calabar ranged between 0.4218 and 0.6949 . The lowest values of albedo obtained in the months of February for Gusau and January for Calabar are during the dry season when it was relatively cloudless and dustless. The values of the albedo obtained for this study areas under investigation compares favourably well with previous studies such as that of Babatunde et al. [4] where they obtained the albedo for Ilorin, Nigeria ranging between 0.361 and 0.644 . The highest albedo recorded was 0.644 at the peak period of cloud activity in August and the lowest was 0.361 in November when it was relatively cloudless and dustless. Audu et al. [7] estimated the albedo for Kano, Nigeria. In their studies they obtained maximum albedo of 0.58 in August (the peak of cloud activity) while the minimum albedo of 0.41 in November (the onset of dry season). In another development, Audu and Isikwue [9] adopt the model for shortwave solar energy balancing at the edge of Earth atmosphere to estimate the albedo for Makurdi, Nigeria. The results indicated that the highest albedo of 0.7 in August and the lowest of 0.5 in November were obtained. Akpootu and Iliyasu [1] obtained the highest and lowest values of albedo simulated for Sokoto to be in the months of August and November with 0.4925 and 0.3185 
respectively. Barka et al. [11] developed a multivariate model to determine the albedo of some selected sites in the Republic of Chad. The RMSE, MAE and MAPE values obtained were $0.035,0.027$ and 7.58 respectively.

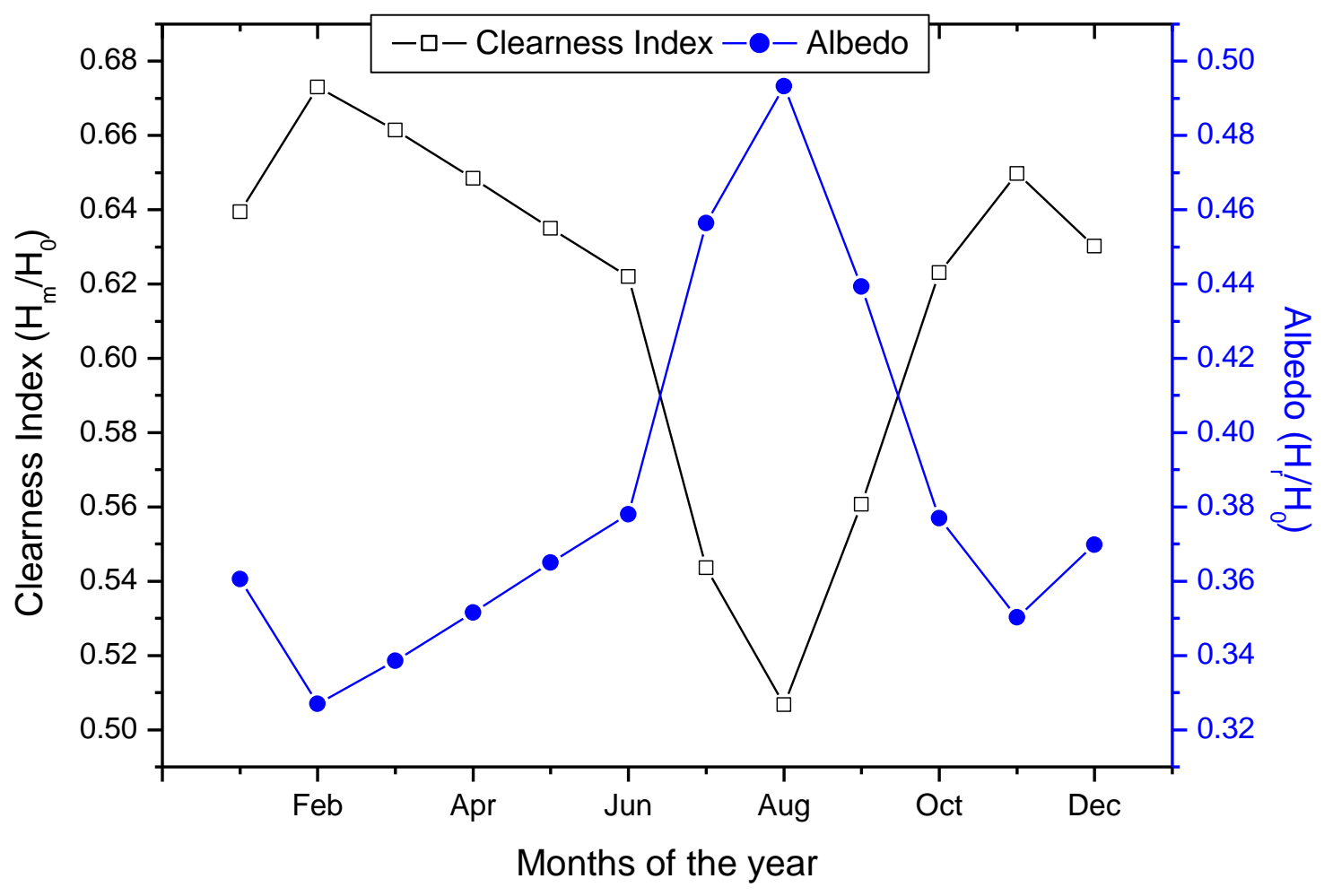

Figure 4. Comparison between Albedo and Clearness Index for Gusau

Figure 4 compares the variation of the reflectance, reflectivity or albedo and the clearness index for Gusau during the study period. It can be seen from the figure that the reflectance have opposite characteristics to the clearness index. The magnitude of the reflectance or albedo indicates the degree of the surface brightness and the amount of the global solar radiation reflected back to space. Thus, when the sky is relatively cloudless, albedo or reflection coefficient would be relatively small, therefore, more radiation would be available to solar energy devices on the Earth. The measured global solar radiation $\left(H_{m}\right)$ and the shortwave reflected radiation $\left(H_{r}\right)$ are fractions of the extraterrestrial radiation $\left(H_{0}\right)$, therefore, the clearness index and reflectance can be compared. The values of the clearness index are more than those of the reflectance, throughout the months for the period under investigation for Gusau, the consequence of this, is that, since the global solar radiation is towards the ground surface and the shortwave reflected radiation is towards the space, therefore, the global solar radiation received on the Earth's surface is more than the reflected radiation lost to space throughout the months in the location; signifying the availability of abundant solar radiation in the region. The highest value of albedo and the lowest value of clearness index were found in August. This is where the region is said to have its peak value during the rainy season. The highest and lowest values of clearness index was observed in the months of February and August with 0.6730 and 0.5067 respectively while the highest and lowest values of albedo was observed in the months of August and February with 0.4933 and 0.3270 respectively verifying their opposite relationship as illustrated in the figure. 


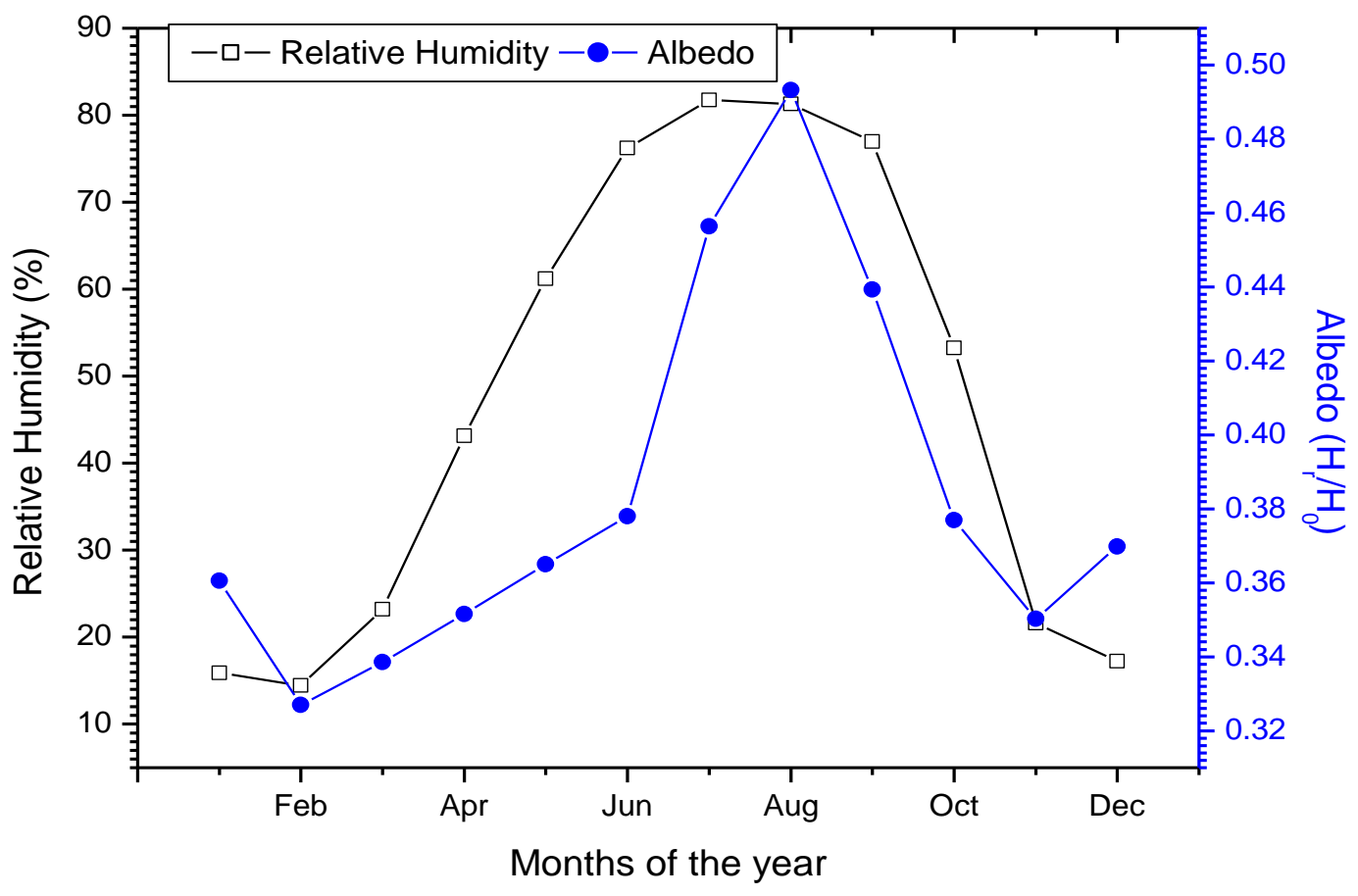

\section{Figure 5: Variation of monthly mean relative humidity with Albedo for Gusau}

Figure 5 shows the monthly variation of relative humidity with albedo for Gusau during the period under investigation. The figure showed that the pattern of variation of relative humidity with albedo have almost similar trend; indicating that the moisture content in the atmosphere may reliably predicts the values of albedo as a direct variation. The relative humidity and albedo decreases slightly from January to their respective minimum values in February. They both increase subsequently from February until the relative humidity attained its maximum value of $81.7522 \%$ in July while the albedo in August with 0.4933 . The relative humidity and albedo decreases from their maximum values until the relative humidity reaches December while the albedo decreases to November and slightly increases to December.

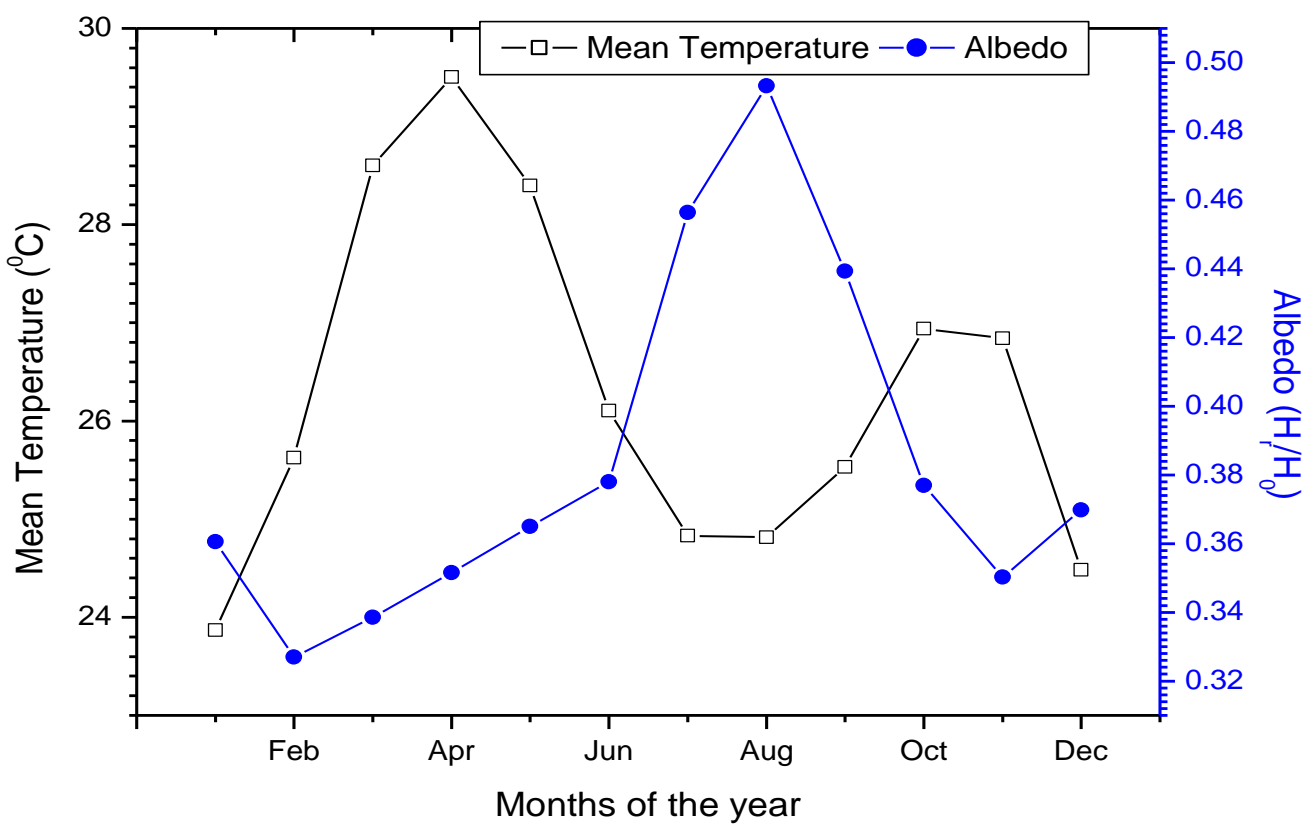

Figure 6: Variation of monthly mean temperature with Albedo for Gusau 
Figure 6 shows that the temperature increases from its minimum value of $23.8667{ }^{0} \mathrm{C}$ in January and attained its maximum value in April while the albedo decreases slightly from January to its minimum value of 0.3270 in February and increases subsequently to its maximum value in August. The figure revealed that as the temperature decreases from its maximum value in April to August, the albedo increases. It can be seen that the temperature increases from August to October and decreases from October to December; the albedo decreases from August to November and increases slightly to December. It was observed that the temperature decreases from October to February. This is the cold season for the study area when the climate is dominated by harmattan wind blowing sahara dust over land. It was expected that the temperature should increase just like most of the coastal regions in Nigeria, but, decreases because of the dust particles in the atmosphere that dims the sunlight.

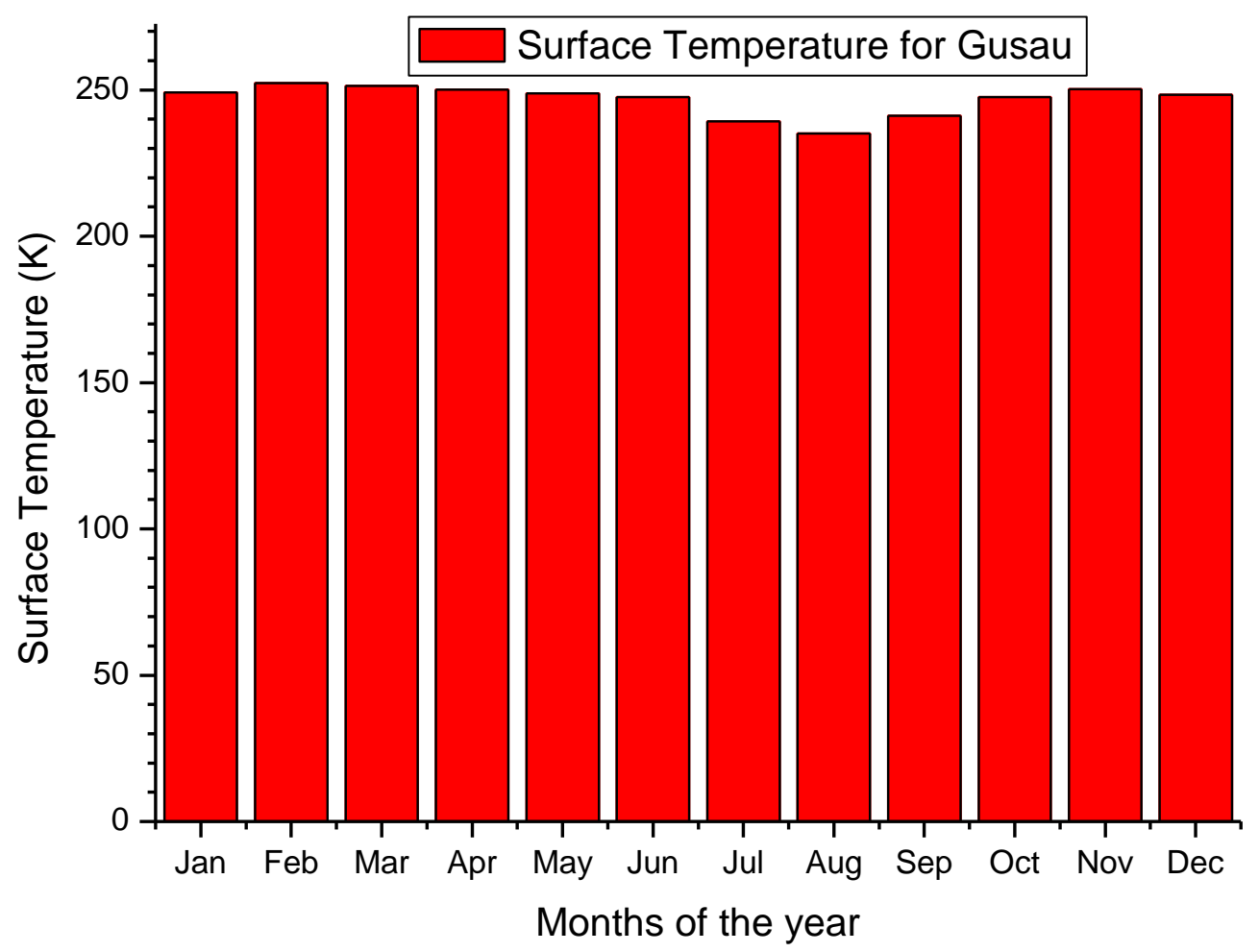

Figure 7. Monthly mean emitting Earth surface temperature for Gusau

Figure 7 shows the variation of the emitted temperature by the Earth for Gusau. The highest emitting Earth surface temperature was observed in the month of February $(252.4133 \mathrm{~K})$ as this is expected because the albedo is low during this period, thereby allowing more radiation into the Earth which consequently increases the temperature. The lowest emitting Earth surface temperature was observed in the month of August $(235.1297 \mathrm{~K})$, this is the most cloudy month for this region, where the rainy season is at its peak; the low temperature is expected, due to high reflection of solar radiation. In this location, the emitting Earth surface temperature ranged between the values of $235.1297 \mathrm{~K}$ to $252.4133 \mathrm{~K}$ which compares favourably well with the standard value for the emitting surface temperature of the Earth $(255.0000 \mathrm{~K})$ at albedo of 0.300 [19]. The results revealed that there is an inverse relationship between the Earth emitting surface temperature and the planetary albedo. 


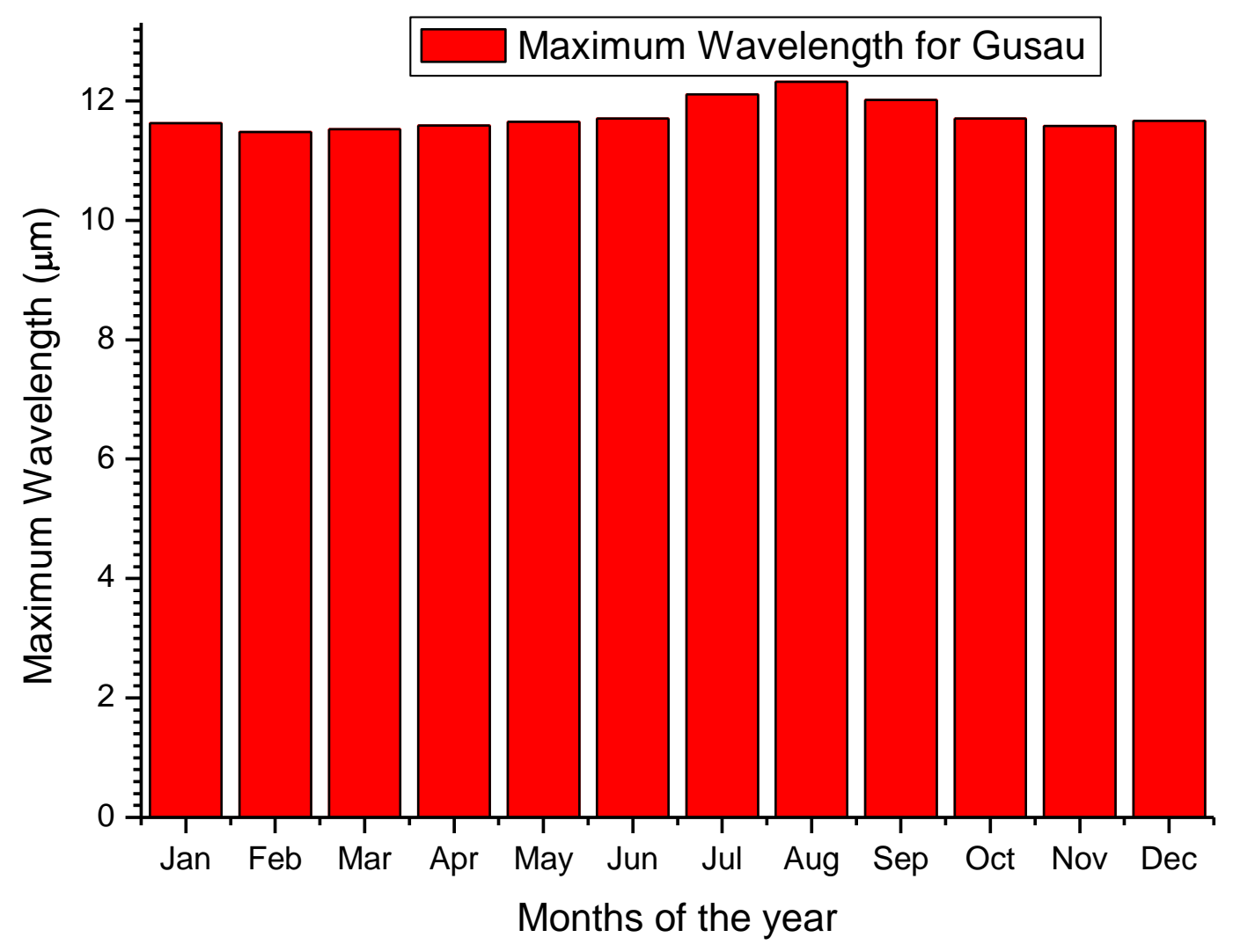

Figure 8. Monthly mean maximum wavelength for Gusau

Figure 8 shows the variation of monthly average daily maximum emitting wavelength for the Gusau. The highest peak wavelength was estimated in the month of August $(12.3309 \mu \mathrm{m})$ and the lowest in the month of February $(11.4772 \mu \mathrm{m})$. The peak wavelength ranged in the values between $11.4772 \mu \mathrm{m}$ to $12.3309 \mu \mathrm{m}$ this values agrees with that reported in radiative transfer literatures, that for longwave radiation $(\lambda>4)$ [19] this shows that the radiation is terrestrial (Earth emitted), and therefore within the infrared region. 


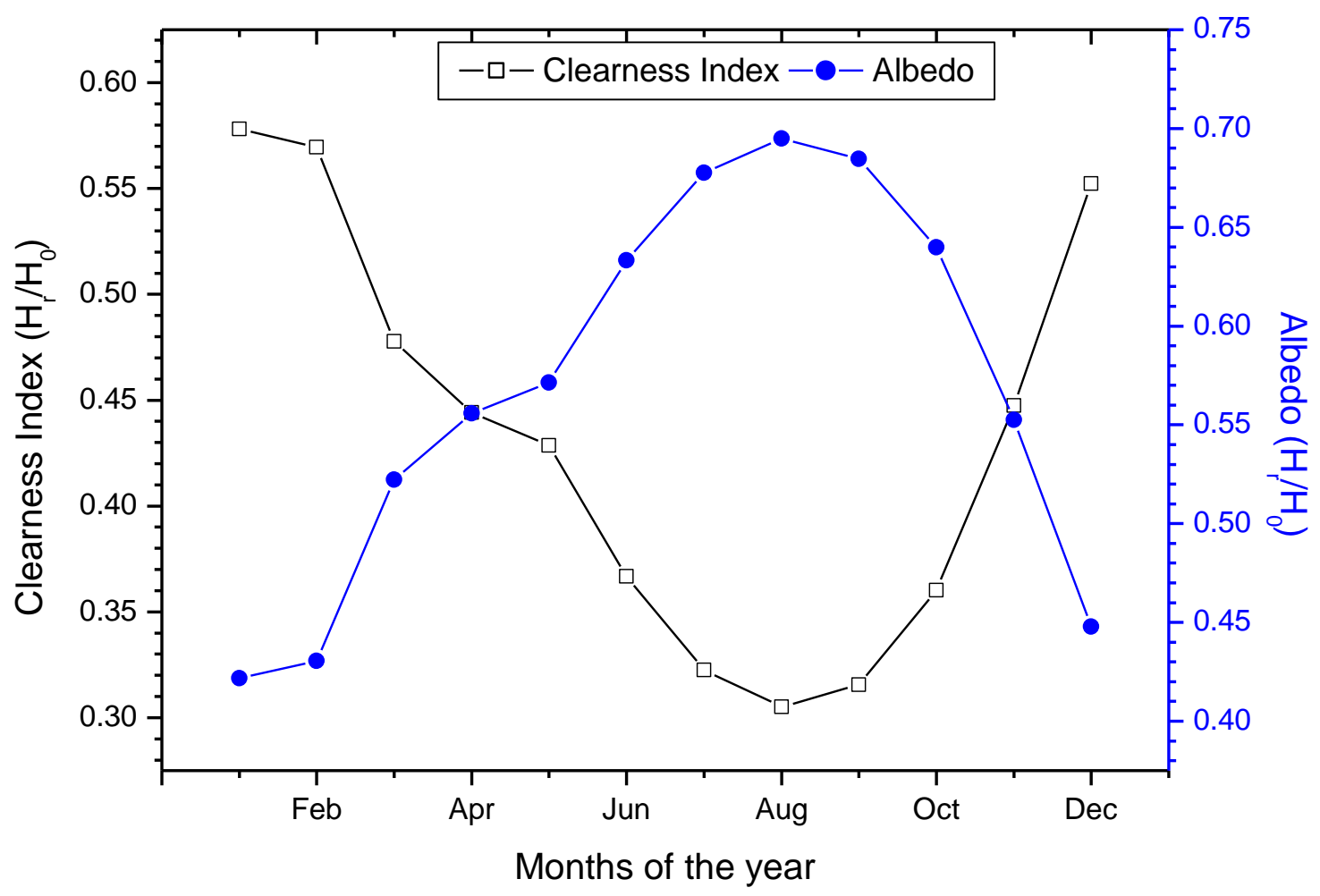

Figure 9. Comparison between Albedo and Clearness Index for Calabar

Figure 9 compares the variation of the reflectance, reflectivity or albedo and the clearness index for Calabar during the study period, the figure illustrated that the reflectance/albedo have opposite characteristics to the clearness index. The magnitude of the reflectance suggests the degree of brightness of the surface and the amount of the solar radiation reflected back to space. Hence, when the sky is relatively cloudless, albedo or reflection coefficient would be relatively small, in this regard; more radiation would be available to solar energy devices on the Earth. The measured solar radiation $\left(H_{m}\right)$ and the shortwave reflected radiation $\left(H_{r}\right)$ are individually fractions of the extraterrestrial radiation $\left(H_{0}\right)$, thus, the clearness index and reflectance can be compared. The values of the clearness index are only more than those of the reflectance/albedo in the months of January, February and December for Calabar. Since the global solar radiation is towards the ground surface and the shortwave reflected radiation is towards the space, thus, the global solar radiation received on the Earth's surface is less than the reflected radiation lost to space in the study area. The highest value of albedo corresponds to the lowest value of clearness index in August; this is where the region is said to have its peak value during the rainy season. The highest and lowest values of clearness index was observed in the months of January and August with 0.5782 and 0.3051 respectively while the highest and lowest values of albedo was observed in the months of August and January with 0.6949 and 0.4218 respectively authenticating their opposite relationship as displayed in the figure. 


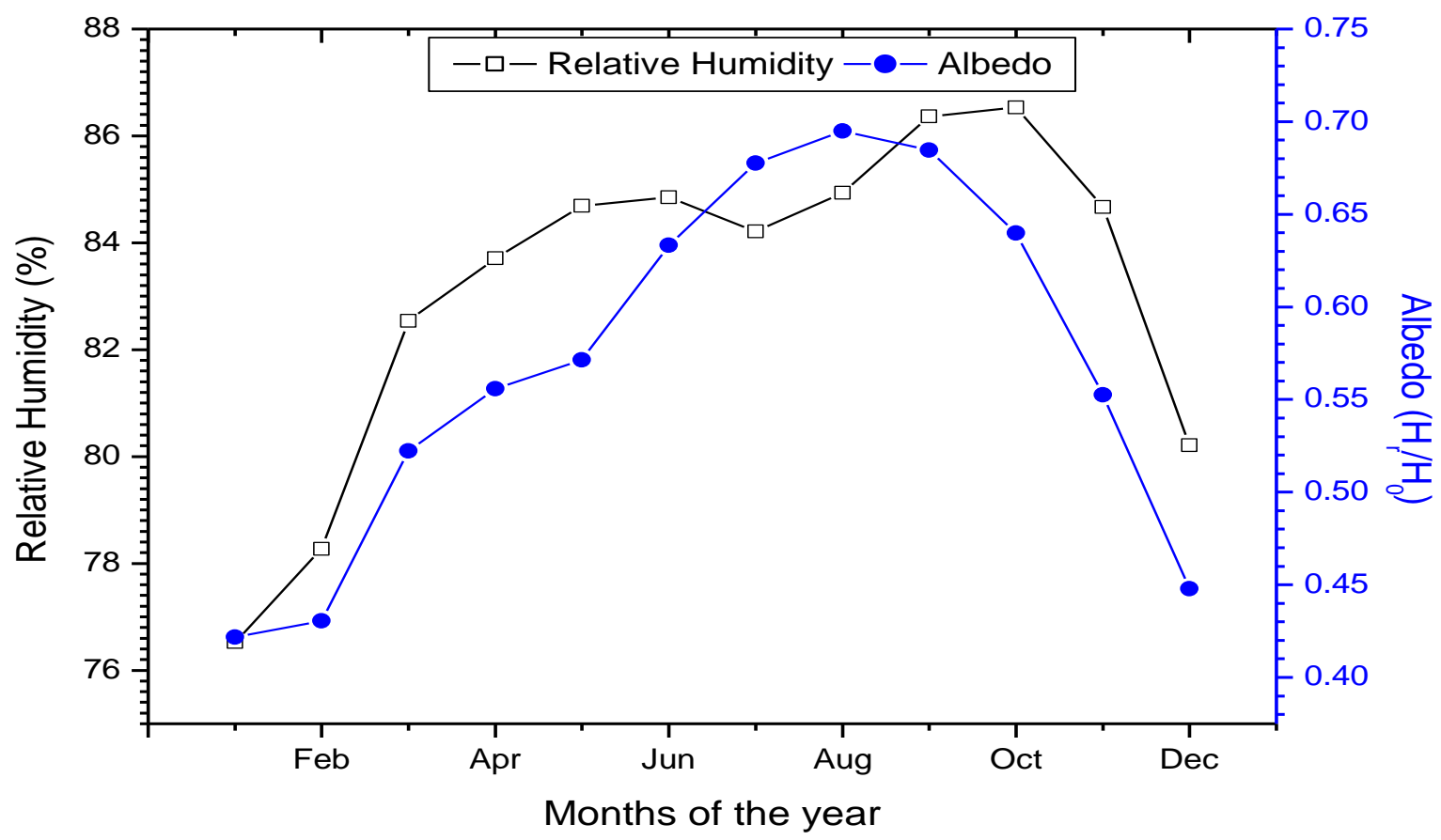

Figure 10. Variation of monthly mean relative humidity with Albedo for Calabar

Figure 10 shows that the patterns of variation of relative humidity with albedo for Calabar have almost similar trend suggesting that the moisture content in the atmosphere may reliably give reasonable estimates of the albedo. The relative humidity and albedo increases from their minimum values in January until when the albedo attained its maximum value in August and decreases subsequently from August to December. As the relative humidity reaches June it decreases slightly in July and increases subsequently from July and attained its maximum value of $86.5349 \%$ in October and decreases to December.

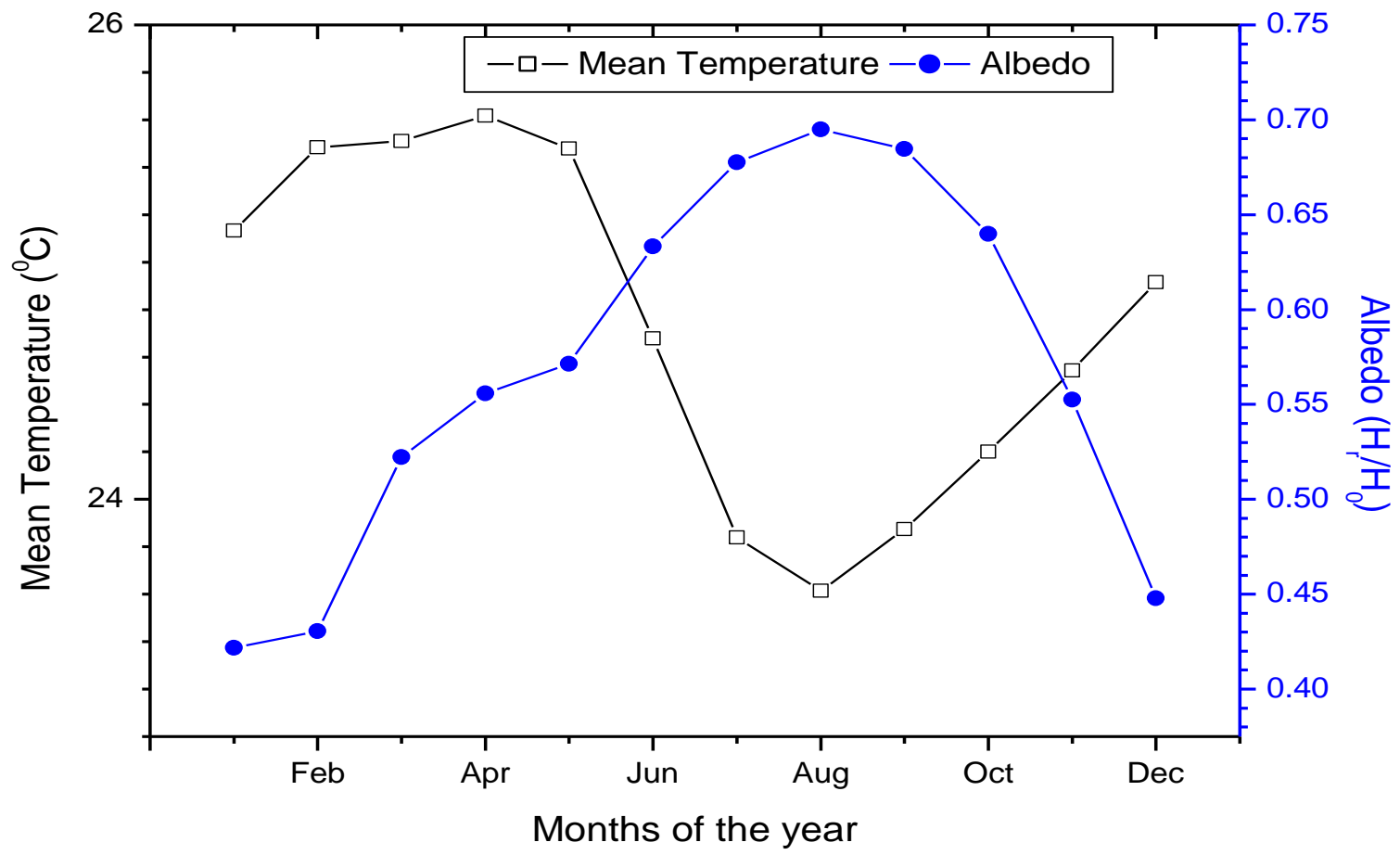

Figure 11. Variation of monthly mean temperature with Albedo for Calabar 
Figure 11 shows the variation of temperature with albedo for Calabar. The temperature increases slightly from January and attained its maximum value of $25.6170{ }^{\circ} \mathrm{C}$ in April and decreases subsequently from April and attained its minimum value in August. The albedo on the other hand, increases from its minimum value in January; and attained its maximum value in August; the maximum value of albedo in August corresponds to the minimum value of temperature in August. This period of August break is where the location recorded the highest rainfall, though, there is a short dry period. It is obvious from the figure that as the temperature increases from its minimum value in August to December, the albedo decreases from its maximum value in August to December.

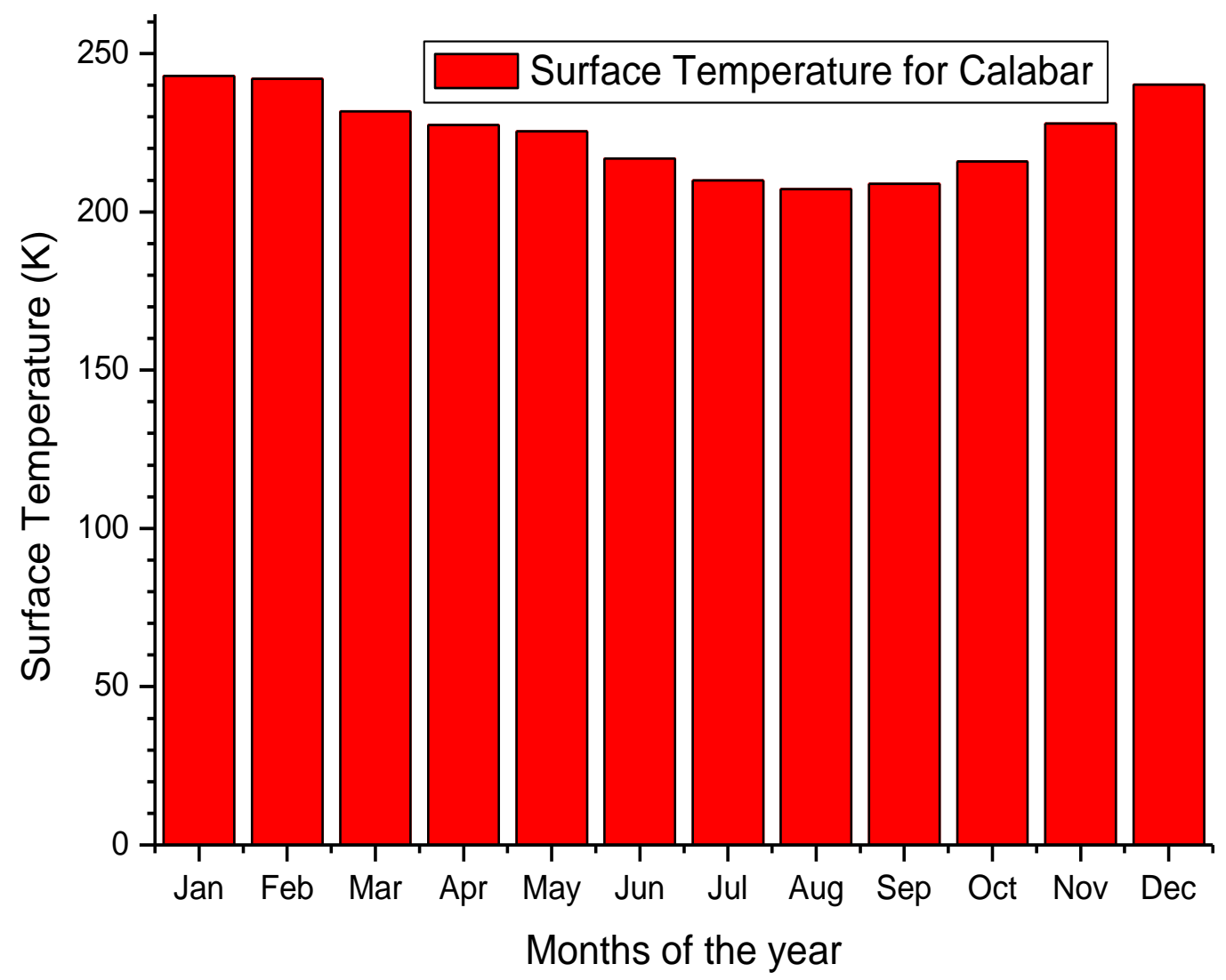

Figure 12. Monthly mean emitting Earth surface temperature for Calabar

Figure 12 shows the variation of the emitted temperature by the Earth for Calabar. The highest emitting Earth surface temperature was found in the month of January $(243.0097 \mathrm{~K})$ as this is expected because the albedo is low during this period, thereby allowing more radiation into the Earth which consequently increases the temperature. The lowest emitting Earth surface temperature was found in the month of August (207.1236 K), this is the most cloudy month for this region, where the rainy season is at its peak; the low temperature is expected, due to high reflection of solar radiation. In this location, the emitting Earth surface temperature ranged between the values of $207.1236 \mathrm{~K}-243.0097 \mathrm{~K}$ which compares favourably well with the standard value for the emitting surface temperature of the Earth $(255.0000 \mathrm{~K})$ at albedo of 0.300 [19]. The results revealed that an inverse relationship exists between the Earth emitting surface temperature and the planetary albedo. 


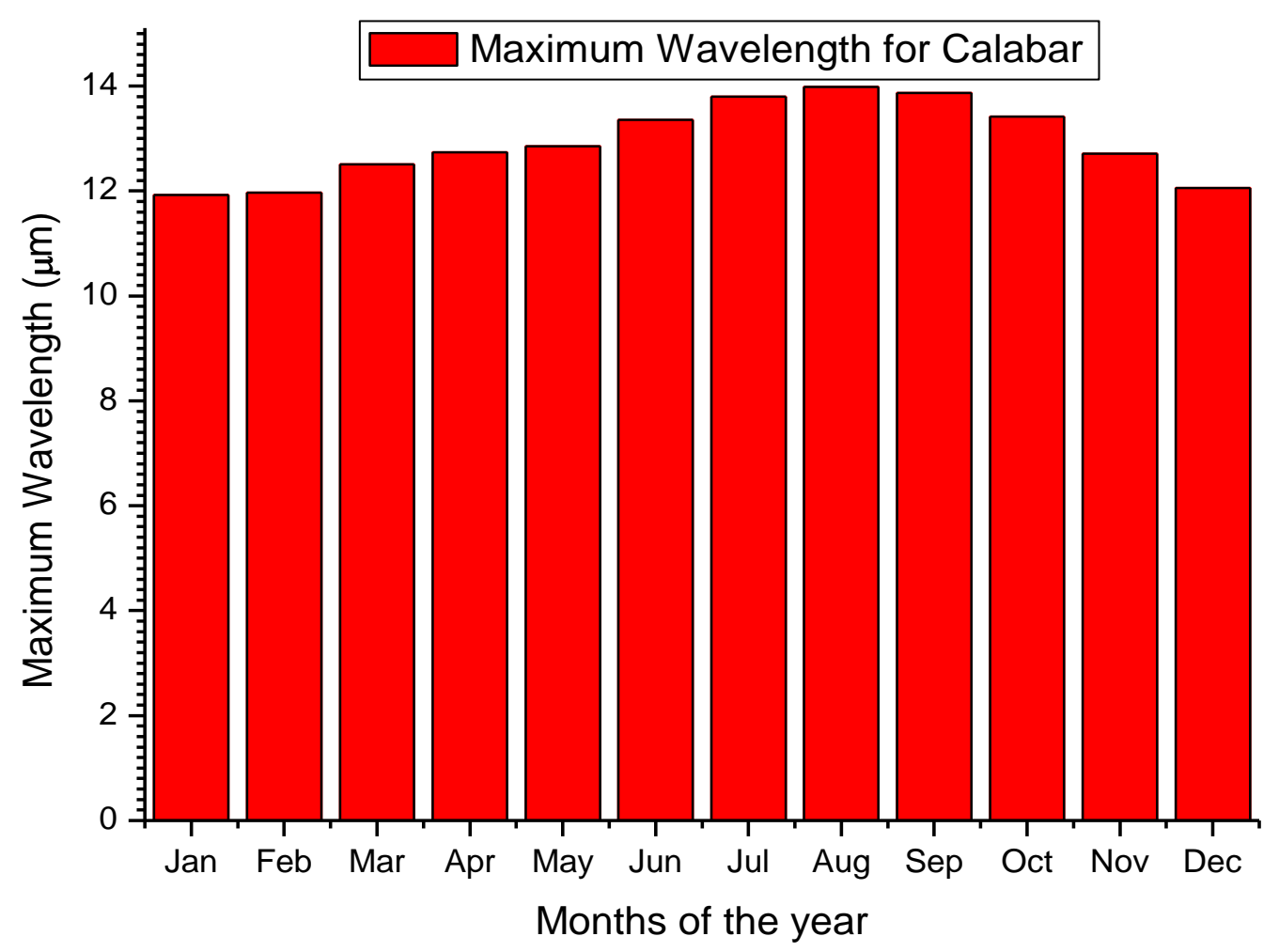

Figure 13. Monthly mean maximum wavelength for Calabar

Figure 13 shows the variation of monthly average daily maximum emitting wavelength for Calabar. The highest peak wavelength was estimated in the month of August $(13.9868 \mu \mathrm{m})$ and the lowest in the month of January $(11.9213 \mu \mathrm{m})$. The peak wavelength ranged in the values between $11.9213 \mu \mathrm{m}$ to $13.9868 \mu \mathrm{m}$ this values agrees with that reported in radiative transfer literatures, that for longwave radiation $(\lambda>4)[19]$ this shows that the radiation is terrestrial (Earth emitted), and therefore within the infrared region.

\section{CONCLUSION}

This study estimates and compared the variation of surface albedo for two tropical locations, Gusau (Latitude $12.17^{0} \mathrm{~N}$, Longitude $6.70^{\circ} \mathrm{E}$ and altitude $463.9 \mathrm{~m}$ above sea level) and Calabar (Latitude $4.97^{\circ} \mathrm{N}$, Longitude $8.35^{\circ} \mathrm{E}$ and altitude $61.9 \mathrm{~m}$ above sea level) situated across the Sahelian and Coastal climatic zones of Nigeria using measured monthly mean daily global solar radiation data obtained from the National Aeronautics and Space Administration (NASA) during the period of twenty two years (July 1983 June 2005). The method of shortwave solar energy balancing at the edge of the Earth's atmosphere was employed in the estimation of surface albedo. The variation of albedo with clearness index, relative humidity and mean temperature were investigated. Also, the variation of emitting Earth's surface temperature and maximum wavelength for each month during the period under investigation was studied. The highest and lowest values of albedo estimated for Gusau were found to be in the months of August and February with 0.4933 and 0.3270 respectively while for Calabar are in the months of August and January with 0.6949 and 0.4218 respectively. The comparison between the estimated albedo for Gusau and Calabar showed that the values of albedo for Calabar are higher than that of Gusau in each month during the period under study suggesting that as the latitude and global solar radiation of a location increases the values of albedo decreases. The estimated albedo in this study are in good agreement with previous studies and are within the range of surface albedo values found for different locations by different researchers varying from 0 for no reflection to 1 for complete reflection of light striking the surface. The clouds, aerosols, air molecules and particles are the basic atmospheric factors influencing the reflection and scattering of solar radiation of which the clouds is the major contributing factor. The variation of clearness index with albedo revealed that the clearness index is higher than the albedo throughout the months for Gusau suggesting abundant global solar radiation throughout the years during the study period. The clearness index is only more than the albedo in January, February and December for Calabar. The emitting Earth surface temperature for Gusau ranged between 235.1297 K in August and 252.4133 K in February while for Calabar ranged between 207.1236 K in August and 243.0097 K in January, these values compares favourably well with the standard emitting 
Earth surface temperature value $(255.0000 \mathrm{~K})$. The maximum emitting wavelength ranged between $11.4772 \mu \mathrm{m}$ in February and $12.3209 \mu \mathrm{m}$ in August for Gusau while for Calabar ranged between $11.9213 \mu \mathrm{m}$ in January and $13.9868 \mu \mathrm{m}$ in August; these values shows that the radiation in these regions are longwave radiation $(\lambda>4)$ as expected and fall within the infrared region of the electromagnetic spectrum. The variation of relative humidity with albedo depicts almost similar trend for both locations as both parameters increases and decreases during the rainy and dry seasons respectively. The variation of albedo with temperature showed that as albedo increases during the rainy season the temperature decreases; similarly, as albedo decreases during the dry season the temperature increases.

\section{ACKNOWLEDGEMENTS}

The authors wish to appreciate the management and staff of the National Aeronautics and Space Administration (NASA) atmospheric science data centre under Surface meteorology and Solar Energy for making all the relevant data used in this present study available online. The contribution and suggestions of the anonymous reviewers are well appreciated.

\section{REFERENCES}

[1] Akpootu, D. O and Iliyasu, M. I. (2017). Estimation of the Monthly Albedo of the Earth's Atmosphere over Sokoto, Nigeria. Archives of Current Research International., 7(3): 1-10. DOI: 10.9734/ACRI/2017/33196

[2] Burari, W. F and Sambo, S. A. (2001). Model for the prediction of global solar radiation for Bauchi using meteorological data. Renewable Energy. 9(1\&2):30-33.

[3] Iqbal, M. (1983). An introduction to solar radiation, first ed. Academic Press, New York.

[4]. Babatunde, E. B, Falaiye, O. A and Uhuegbu, C. C (2005). Simulated reflection SW-radiation and its characteristic variation at Ilorin, Nigeria. Nigeria Journal of Physics. 175:193- 201.

[5] Gutman, G. (1988). A simple method for estimating monthly mean albedo of land surfaces from AVHRR data. Journal of Applied Meterology. 27(27):973-984.

[6] Prado, R. T. A and Ferreira, F. L (2005). Management of albedo and analysis of its influence on the surface temperature of building materials. Energy and Buildings. 37(4):295-301.

[7] Audu, M. O., Isikwue, B. C and Eweh, J. E (2014). Estimation of Seasonal and Annual Albedo of the Earth's Atmosphere over Kano, Nigeria. IOSR Journal of Applied Physics. 6(5):56-62.

[8]. Babatunde, E. B. (2012). Surface Albedo Estimation and Variation Characteristics at a Tropical Station, Solar Radiation, Prof. Elisha B. Babatunde (Ed.), ISBN: 978-953-51-0384-4, InTech, Available from: http://www.intechopen.com/books/solarradiation/surface-albedo-estimation-and-variation-characteristics-at-atropical-station

[9] Audu, M. O and Isikwue, B. C (2014). Estimation of the Albedo of the Earth's atmosphere at Makurdi, Nigeria. International Journal of Scientific and Technology Research.3(4):375-380.

[10] De sonsa, J. L., Nicacio, M and Monra, M. A. L (2005). Solar radiation measurements in Maceio, Brazil. Renewable Energy. 30:1203-1220.

[11] Barka, Z. M., Lealea, T and Tchinda, R. (2018). Estimation of the earth's albedo over some selected area the Republic of Chad. International Journal of Physical Research., 6(2). 64 - 69. doi: 10.14419/ijpr.v6i2.15846

[12] Agunlejika, O and Raji, T. I (2010). Empirical evaluation of wet-term of refractivity in Nigeria. International Journal of Engineering and Applied Sciences (IJEAS). 2(2): 63-68.

[13] Olaniran, O. J (1983). The Monsoon factor and the seasonality of rainfall distribution In Nigeria, Malaysian J Trop Geog, 7 : pp $38-45$.

[14] Akpootu, D. O., Tijjani, B. I and Gana, U. M. (2019). Sunshine and Temperature Dependent Models for Estimating Global Solar Radiation Across the Guinea Savannah Climatic Zone of Nigeria. American Journal of Physics and Applications. Vol. 7 , No. 5, 2019, pp. 125-135. doi: 10.11648/j.ajpa.20190705.15.

[15] Zekai, S (2008). Solar energy fundamentals and modeling techniques: atmosphere, Environment, climate change and renewable energy, first ed. Springer, London.

[16] Babatunde, E. B (2003). Some solar radiation ratios and their interpretations with regards to radiation transfer in the atmosphere. Nig. J. of Pure and Appl. Sc. In press. 4.

[17] Babatunde, E. B and Aro, T. O (1995). Relation between clearness index and cloudiness index. Renewable Energy. 6(7):801805.

[18] Udo, S. O (2000). Sky conditions at Ilorin as charcterized by clearness and relative sunshine. Solar Energy. 69(1):45-53.

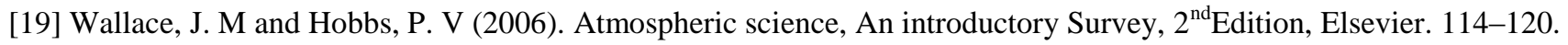

[20].McIIveen, R. (1992). Fundamental of weather and Climate. McGraw Hill 